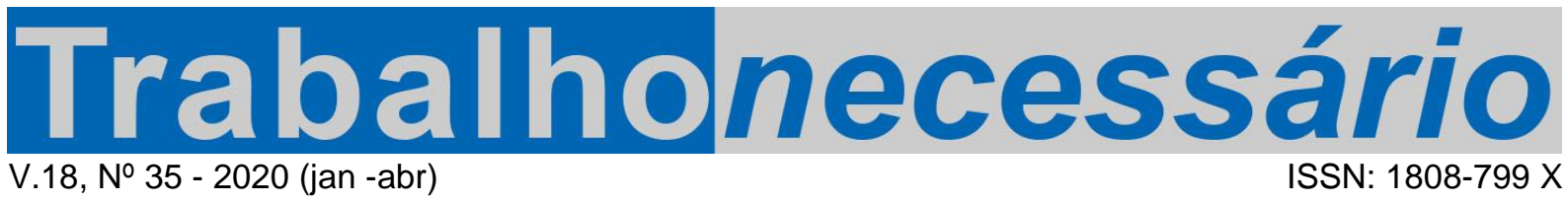

DOI: https://doi.org/10.22409/tn.v18i35.40492

\title{
O REDUCIONISMO DA PERSPECTIVA DE DESENVOLVIMENTO HUMANO COMO EFEITO DA LIQUEFAÇÃO DAS NECESSIDADES HUMANAS NO MERCADO CAPITALISTA ${ }^{1}$
}

Maria de Fatima Felix Rosar ${ }^{2}$

\begin{abstract}
Resumo
O artigo aborda as relações entre capital, trabalho e desenvolvimento humano, enfatizando processos de produção e exploração da força de trabalho. Trata da indústria sustentada pelo trabalho de crianças, mulheres e homens, da reestruturação produtiva e seus efeitos sobre a subjetividade humana. Revisita textos de Marx sobre as necessidades humanas no capitalismo e as necessidades qualitativas possíveis no pós-capitalismo. Destaca a exploração dos trabalhadores, sob formas violentas e edulcoradas, propondo reflexões para se resistir ao reducionismo da perspectiva de desenvolvimento humano.

Palavras-chave: Capital; Trabalho; Desenvolvimento Humano

\section{EL REDUCIONISMO DE LA PERSPECTIVA DEL DESARROLLO HUMANO COMO EFECTO DE LIQUIFICAR LAS NECESIDADES HUMANAS EN EL MERCADO CAPITALISTA}

\section{Resumen}

El artículo aborda la relación entre capital, trabajo y desarrollo humano, enfatizando los procesos de producción y explotación de la fuerza laboral. Se trata de la industria apoyada por el trabajo de niños, mujeres y hombres, la reestructuración productiva y sus efectos sobre la subjetividad humana. Revisa los textos de Marx sobre las necesidades humanas en el capitalismo y las posibles necesidades cualitativas en el pos-capitalismo. Destaca la explotación de los trabajadores, en formas violentas y endulzadas, proponiendo reflexiones para resistir el reduccionismo de la perspectiva del desarrollo humano.

Palabras-clave: Capital; Trabajo; Desarrollo humano

\section{THE REDUCIONISM OF THE HUMAN DEVELOPMENT PERSPECTIVE AS AN EFFECT OF LIQUIFYING HUMAN NEEDS IN THE CAPITALIST MARKET}

\begin{abstract}
The article addresses the relationship between capital, labor and human development, emphasizing processes of production and exploitation of the workforce. It deals with the industry sustained by the work of children, women and men, the productive restructuring and its effects on human subjectivity. Revisits Marx's texts on human needs in capitalism and the possible qualitative needs in post-capitalism. It highlights the exploitation of workers in violent and sweetened forms, proposing reflections to resist the reductionism of the perspective of human development.
\end{abstract}

1 Artigo recebido em 14/10/2019. Primeira avaliação em 31/10/2019. Segunda Avaliação em 25/11/2019. Aprovado em 06/01/2020. Publicado em 23/01/2020.

2 Professora aposentada da Universidade Federal do Maranhão. Doutorado pela Unicamp em Filosofia e História da Educação, Estágio de Pós-Doutorado na USP. Pesquisadora do Grupo de Estudos e Pesquisas em História Sociedade e Educação (HISTEDBR).E-mail: mffrosar@uol.com.br. ORCID: https://orcid.org/0000-0002-3238-9191. 
Keywords: Capital; Job; Human Development 


\section{Introdução}

Produziu-se no Brasil uma farta e rica produção científica dedicada aos temas do desenvolvimento humano, da educação e de sua relação com o trabalho, à luz da concepção histórico-dialética da realidade, cujos fundamentos encontram-se na história e na historiografia crítica. Foram construídas referências fundamentais para essa compreensão por meio dos textos de Dermeval Saviani, Gaudêncio Frigotto, Maria Ciavatta, Marise Ramos, Lucília Machado, Acácia Kuenzer e muitos outros pesquisadores que delinearam esse campo de conhecimento científico na área da história e política da educação.

Nos anos 1980, particularmente no Brasil, durante uma década florescente para a expansão das concepções críticas acerca da educação e da sociedade, foi possível superar a visão do humanismo ingênuo e da referência à moral, sob o manto da hipocrisia, segundo a qual o trabalho seria sempre a chancela da dignificação humana e a educação um processo necessário e indispensável para o condicionamento dos seres humanos aos modos de vida existentes no campo e na cidade.

Traduzindo-se essa concepção em contextos que contêm elementos reproduzidos até a atualidade, em escalas e modos diferenciados, crianças, jovens e adultos foram sendo conduzidos para o trabalho, como forma de garantir a própria sobrevivência e, portanto, seu "desenvolvimento" resultante do esforço físico, neuropsíquico e emocional, sem o qual poderiam ser condenados à miséria e à fome.

Entretanto, a realidade vivida pelos milhares de seres humanos deslocados de suas terras de origem, aprisionados e exportados do continente africano para o Brasil e também a situação histórica dos habitantes originais do próprio território brasileiro, escravizados pelos colonizadores sob as bênçãos dos representantes das ordens religiosas, que aportaram o novo mundo para "a domesticação dos selvagens", constituem a demonstração suficiente de que a relação entre trabalho e condição digna de vida não se sustenta no âmbito das relações sociais de produção, desde os primórdios da história do Brasil.

Essa concepção de caráter ideológico de educação, trabalho, dignidade e desenvolvimento humano obscureceu a compreensão do dinâmico e contraditório nexo entre capital e trabalho, que se materializou, de modo geral, a partir da gênese do modo de produção implantado pela Revolução Industrial, nos séculos XVIII e XIX. Para implantar, expandir e consolidar o processo de acumulação capitalista, fez-se 
necessário dinheiro, máquinas e corpos humanos levados ao esgotamento nas linhas de produção do primitivo sistema fabril, em que trabalhavam durante 15 horas crianças, homens e mulheres em troca de um mísero salário insuficiente para a reprodução de sua existência física. Foi nesse contexto de violência física instaurada em relação às crianças, que começaram a ser definidas as leis de regulação desse tipo de trabalho infantil, como a Chimney Sweepers Act of $1788 .^{3}$ No entanto, esse processo de regulação demorou a se efetivar de fato. Somente em 1833, o governo britânico publicou uma lei sobre o trabalho nas indústrias têxteis (Factory Act of 1833), especificando as condições a serem observadas em relação ao trabalho infantil ${ }^{4}$.

Em consequência desse processo violento de exploração de trabalhadores e trabalhadoras, muitas reações ocorreram, desde a investida dos luditas ingleses contra as máquinas até a transformação do sistema de produção, em grande medida, como resultado também da luta, resistência e organização dos trabalhadores, como os macartistas do século XIX. Desde a primeira, a segunda, a terceira e, atualmente, a quarta Revolução Industrial, máquinas e homens se confrontam. Os modos de subordinação dos humanos ao componente constante do capital foram progressivamente realizando a sua subsunção formal e real ${ }^{5}$ até se alcançar a automação e robotização, no atualíssimo modo de produção de objetos, ideias e sonhos transformados em mercadorias, que materializam e contrapõem: riqueza e escassez, excesso e miséria, distribuídos conforme a estrutura de classes sociais que se reproduzem, desde a consolidação do capitalismo, como modo de ordenamento das sociedades modernas.

A Primeira Revolução Industrial fez emergir o setor fabril, desencadeando um amplo processo de produção e consumo, ao mesmo tempo que permitiu a expansão

\footnotetext{
3 "Já em 1788, uma primeira lei, a Chimney Sweepers Act of 1788 , visava a impor limites etários à exploração da mão de obra de crianças na limpeza de chaminés, muito embora, somente com a Lei Chimney Sweepers Act, publicada em 1875, as regras quanto ao trabalho de crianças neste ofício conseguiriam ser aplicadas pelo Estado britânico". (JUNIOR; VASCONCELLOS, 2017, p. 278).

4 "Essa lei: a) proibia o emprego de menores de nove anos; b) determinava que os empregadores deveriam manter um certificado de idade das crianças trabalhadoras; c) limitava o máximo de 9 horas por dia de trabalho para as crianças entre 9 e 13 anos; d) limitava o máximo de 12 horas por dia para o trabalho de crianças entre 13 e 18 anos; e) proibia o emprego de crianças no trabalho noturno; f) especificava a obrigação de duas horas de estudo por dia para as crianças; g) criava o cargo de inspetor de fábricas (United Kingdom, 1933a)". (JUNIOR; VASCONCELLOS, 2017, p. 280).

${ }^{5} \mathrm{~A}$ subsunção formal expressa a separação entre a força de trabalho e os meios de produção e possibilita a inserção do trabalhador no processo de valorização do capital, por meio da produção da mais-valia absoluta. A subsunção real resultante do processo de desenvolvimento da ciência e da tecnologia, aplicada aos processos produtivos, possibilita intensificar os ritmos de trabalho, produzindo a mais-valia relativa, materializando-se ainda mais profundamente a alienação do trabalhador, reduzido à condição de apêndice da máquina. (MARX, 1985).
} 
de relações comerciais ultramarinas, entre 1760 e 1850, aproximadamente. A Segunda Revolução Industrial possibilitou um processo de aperfeiçoamento de máquinas, equipamentos e tecnologias, principalmente pelo estabelecimento de equipes de pesquisa articuladas com 0 setor industrial e de produção de conhecimentos na área da medicina, do uso de novas fontes de energia (petróleo, eletricidade) e de novos materiais a partir da indústria do aço.

Essas invenções das quais resultou o aumento exponencial dos lucros e da exploração da força de trabalho, atingiu seu ápice na metade do século XIX até o final da Segunda Guerra Mundial, tendo contribuído para que países da Europa, da América e da Ásia mantivessem as negociações de produtos transacionados em mercados compartilhados entre a maioria dos países dos três continentes. Após a Segunda Guerra Mundial, portanto, a partir da metade do século XX até o século XXI, deu-se um processo muito mais ampliado e radical de mudança dos processos produtivos, com a incorporação da biotecnologia, genética, robótica, informática, telecomunicações, do transporte, a ponto de modificar dimensões espaciais e temporais construídas no mercado globalizado, em que a financeirização ${ }^{6}$ da economia mundial tornou-se expandida e preponderante para garantir a lucratividade dos capitalistas.

Com efeito, a reestruturação produtiva ${ }^{7}$, resultante da Terceira Revolução Industrial, possibilitou o aumento da produtividade e, simultaneamente, a redução do trabalho vivo, alterando os eixos do sistema de produção, circulação e consumo. $\mathrm{O}$ meio ambiente e a saúde dos seres vivos têm sido atingidos brutalmente, enquanto o aprofundamento da desigualdade entre as classes sociais multiplica-se, inclusive com os incontáveis desastres naturais e científicos, que atingem a natureza e a humanidade, tais como as guerras, as epidemias, pandemias, ações destrutivas que atingem os ecossistemas, e também agridem frontalmente os seres humanos.

\footnotetext{
6 Processo caracterizado pelo aumento e pela valorização da riqueza financeira, como ações, títulos da dívida pública e privada, bem como os ativos derivados desses, comparativamente aos ativos reais, empregados na produção de bens e serviços que produzem lucros aos seus detentores. No caso dos primeiros, a moeda não faz girar bens e serviços na esfera industrial, mas sim papéis de empresas financeiras, com elevada liquidez, visando aos ganhos com juros e a valorização. Já os ativos produtivos são ilíquidos, constituem o capital produtor de lucros. (ROSAR, 2019).

7 "Sabemos que a partir do início dos anos 1970, o capital implementou um processo de reestruturação em escala global, visando tanto à recuperação do seu padrão de acumulação, quanto procurando repor a hegemonia que vinha perdendo, no interior do espaço produtivo, desde as explosões do final da década de 1960, onde, particularmente na Europa ocidental se desencadeou um monumental ciclo de greves e lutas sociais". (ANTUNES; BRAGA, 2009, p. 233).
} 
Ao mesmo tempo, o processo de reestruturação produtiva tornou predominante a lógica da organização do trabalho, a partir da concepção do toyotismo ${ }^{8}$, porém manteve de forma associada a essa nova matriz as modalidades anteriores de enquadramento dos trabalhadores no processo produtivo, como o taylorismo. Desse modo, o neotaylorismo concorre para a subtração da subjetividade, sobretudo no trabalho realizado pelos empregados nas Centrais de Teleatividades.

Venco, ao analisar o processo de taylorização que se deslocou do setor fabril para a esfera do trabalho das CTAs, identifica "um crescente movimento na organização do trabalho para tentar apropriar-se da subjetividade dos funcionários". (VENCO, 2009, p.159). Segundo Linhart, esse processo aproxima--se "muito mais a um esforço de racionalização e de prescrição da subjetividade coletiva e individual dos assalariados, do que uma renúncia aos princípios fundamentais do taylorismo". (LINHART, 2007, p.117 apud VENCO, 2009, p. 159). Noël Lechat e Jean-Claude Delaunay reconhecem os trabalhadores das Centrais de Teleatividades como "os novos proletários deste novo milênio". Para esses estudiosos, os jovens teleoperadores 9 "não vendem somente sua força de trabalho, mas também seu engajamento emocional e pessoal". (VENCO, 2009, 169).

Observa-se que outro impacto das novas formas de trabalho e de comunicação atingem a privacidade dos indivíduos, transformando-a em conteúdo da esfera pública, em consequência da explosão dos circuitos das redes virtuais, de forma desmesurada e, em grande medida, usadas de modo insano. Por exemplo, no caso de trabalhadores que, individualmente, se insurgem às práticas de dominação e controle do capital, em diversos setores de produção e de serviços, são submetidos rapidamente a processos de desqualificação profissional, por meio de campanhas difamatórias e outras modalidades de assédio moral, tornando-se presa fácil de "milícias" virtuais.

\footnotetext{
8 "Para Coriat (1994), o modelo Toyota inverte as regras tradicionais da lógica fordista, que se assentavam na parcelização das tarefas e separação entre concepção e execução, em que os trabalhadores do chão de fábrica eram desincumbidos de pensar o processo de trabalho ao qual tinham de sujeitar-se. (...) Desta feita, esse sistema, denominado just in time, não preconiza a produção em larga escala, mas sim em lotes de séries menores determinados pelo fluxo da demanda". (MAGNO; BARBOSA, 2011, p.126)

9"Os trabalhadores selecionados por empresas terceirizadoras de teleserviços são predominantemente mulheres, jovens, afrodescendentes, homossexuais, transexuais, obesos, enfim pessoas frequentemente rejeitadas em postos de trabalho que envolvem o contato vis-à-vis, relegando-os a permanecerem invisíveis a uma sociedade de consumo que privilegia certos padrões estéticos". (VENCO, 2009, 170).
} 
Além dessas evidências, recentemente no Brasil, a disseminação sem limites de conteúdos destrutivos acerca de pessoas que ocupam destaque na esfera política tornou-se um fenômeno que ganhou uma dimensão preocupante, sendo hoje objeto de investigação, do ponto de vista policial. Diversas análises sobre as múltiplas dimensões desse fenômeno têm sido divulgadas pelos especialistas da área de filosofia, sociologia, psicologia, psicanálise. Destacam--se algumas obras relevantes, tais como: A sociedade individualizada - Vidas Contadas e Histórias Vividas, Zygmunt Bauman (2008); A reinvenção da intimidade. Políticas do sofrimento cotidiano, Christian Dunker (2017); O privilégio da Servidão - o novo proletariado de serviços na era digital, Ricardo Antunes (2018); The Age of Disruption: Technology and Madness in Computational Capitalism, Bernard Stiegler (2019).

No século $\mathrm{XXI}$, ainda que seja possível constatar a existência de uma amálgama de processos produtivos, englobando formas pregressas de trabalho e de produção, instaurou-se a hegemonia da era da informação digital, transformando radicalmente os conhecimentos, as informações e os dados em bens intangíveis de extraordinário valor agregado para a expansão do capital em sua dimensão fictícia. Já não se pensa a indústria como locus predominantemente reservado à produção de mercadorias, uma vez que se pode dispensar até mesmo a presença dos operários na indústria 4.0. ${ }^{10}$ Aproximadamente, a partir de 2011, foi sendo concebido e materializado o conceito de indústria inteligente e autônoma, na qual a conexão entre máquinas, sistemas e ativos permite que a produção seja ao mesmo tempo controlada pelas redes de computadores, com dispositivos de inteligência artificial capazes de fazer a gestão da produção, controlar todas as fases, identificar falhas no processo e superá-las por meio de readequação automática dos procedimentos em curso, até que se realizem todos os requisitos necessários para a finalização com êxito e garantia de excelência dos produtos. ${ }^{11}$

\footnotetext{
10 "O conceito e Indústria 4.0 é a interconexão de toda a cadeia de valor (Informações + Pessoas + Equipamentos) conectados em rede, utilizando Inteligência Artificial para a TOMADA DE DECISÕES na Indústria. Quanto as tecnologias da Indústria 4.0, há diversas e não queremos limitar o assunto. Todavia, para fins de estudo, precisamos entender que há um pré-requisito para implantação da Indústria 4.0, que passa pela Automação, Otimização e Convergência". https://www.automacaoindustrial.info/manufatura-4-0-x-processo-4-0/

$11 \mathrm{Na}$ ponta desse processo, o imperialismo norte-americano projeta suas novas conquistas e manutenção de sua soberania, apostando na reindustrialização a partir desse novo processo de produção digitalizado. No entanto, não está só: o Japão, a própria Alemanha e, em alguma medida, a China seguem desenvolvendo sua indústria nessa direção com alguma relevância. Rádio Pião Informativo Operário - Ano XV, no76, março/abril, 2019, p.2.
} 
Neste mesmo século, paralelamente ao avanço dos novos métodos de produção, tem crescido o desemprego estrutural, transformando os processos educativos e culturais num subproduto da revolução das máquinas, que definem os novos perfis profissionais adequados a esse processo de automação, por meio do qual, progressivamente, reduz-se o número de trabalhadores necessários para o planejamento, a execução e avaliação dos processos produtivos.

A incorporação dos conhecimentos produzidos cientificamente pelos profissionais responsáveis por conceber e produzir softwares garante que a subsunção do trabalho intelectual ocorra, de modo similar, aos moldes do que se verificou com os trabalhadores fabris, progressivamente expropriados do seu conhecimento, na medida em que trabalhavam em linhas de produção cujos procedimentos operacionais e os produtos deles resultantes passaram a ser objetos das pesquisas e avaliação dos especialistas em "administração empresarial científica".

Os efeitos do processo de subsunção se evidenciam no mercado, no qual se estabelecem novas equações entre capital e trabalho, trabalho vivo e trabalho morto, sempre garantindo a permanência de uma relação cujo resultado predominante reproduz a subordinação e a exploração do trabalho, a ponto de se realizar por diferentes meios de controle a expansão e/ou a retração de setores produtivos, alterando a própria condição de trabalho e de vida do grande contingente de trabalhadores existentes no mundo. Pode-se ter uma noção aproximada desse processo de construção e destruição encetado pelo capital, a partir de dados atualizados da OIT (Organização Internacional do Trabalho).

Um relatório recente da Organização Internacional do Trabalho (OIT) mostra: há agora 3,5 bilhões de trabalhadores no mundo. Nunca o número foi tão vasto. A conversa sobre "o fim dos trabalhadores" é prematura, quando confrontada com o peso desses dados. A OIT reporta que a maior parte desses 3,5 bilhões de trabalhadores "enfrentam ausência de bem-estar material, segurança econômica, igualdade de oportunidades ou possibilidade de desenvolvimento humano. Estar empregado nem sempre garante uma vida decente. Muitos trabalhadores precisam aceitar trabalhos pouco atraentes, normalmente informais (é o chamado trabalho flexível) e caracterizados por baixa remuneração, além do acesso escasso ou inexistente a proteção social e direitos trabalhistas". Embora metade da força de trabalho mundial seja composta por empregados assalariados, dois milhões de trabalhadores (61\% do total) estão no 
setor informal. (PRASHAD, Vijay. Sobre iPhone11, tecnologia e "fim do trabalho", 2019).

Se a maioria dos trabalhadores está composta pelos que participam do setor informal, depreende-se que o domínio da economia, decorrente do modo de produção capitalista, amplia-se quantitativa e qualitativamente, absorvendo as dimensões do trabalho produtivo e do trabalho improdutivo, alcançando desse modo a hegemonia nas esferas da economia, da política, da educação e da cultura, moldando a subjetividade dos "trabalhadores-empreendedores"12, que devem estar preparados para a concorrência e a busca da sua sustentabilidade, mesmo que isso não faça o menor sentido para aqueles despossuídos de capital ou de qualquer outro patrimônio material, para investir em matéria-prima, equipamento e remuneração de auxiliares.

$\mathrm{Na}$ realidade, a expressão política do capital mais contundente projeta-se com a emergência do neoliberalismo na sua primeira fase, pós-crise dos anos 1970, quando impulsiona um retorno ao ordenamento da sociedade, pela via dos postulados do liberalismo clássico, com a definição do Estado mínimo e do predomínio das leis do Mercado, estendendo-se sobre a vida pública e privada dos sujeitos numa sociedade desigual e excludente, sob a direção da burguesia dominante. Mas, a primeira iniciativa de refundação do liberalismo havia ocorrido em 1938, durante o Colóquio Walter Lippmann, no qual se delinearam as bases para duas correntes do pensamento neoliberal que surgiria depois: a corrente austro-americana, com seus representantes mais destacados, como Friedrich $A$. Hayek e Ludwig von Mises por um lado, e a corrente ordoliberal alemã, com Walter Eucken e Wilhelm Ropke. (DARDOT e LAVAL, 2019).

Compreende-se, com Dardot e Laval, que o neoliberalismo trata-se mais fundamentalmente de uma racionalidade política que se tornou mundial e que consiste em impor por parte dos governos, na economia, na sociedade e no próprio Estado, a lógica do capital até a converter na forma das subjetividades e na norma das existências. (DARDOT e LAVAL, 2019, p.2).

A partir dessa concepção, se recolocam os marcos do neoliberalismo que não abrange apenas as medidas de "políticas econômicas monetaristas ou de austeridade,

12 Magno, Attila; Barbosa, Silva. O empreendedor de si mesmo e a flexibilização no mundo do trabalho. Rev. Sociol. Polít., Curitiba, v. 19, n. 38, p. 121-140, fev. 2011. 
de mercantilização das relações sociais ou de ditadura dos mercados financeiros". (DARDOT e LAVAL, 2019, p.2).

O neoliberalismo que atingiu a sua capacidade máxima de expansão e envolvimento dos países da Ásia, Europa e da América, nos anos 1990, por meio da atuação programática dos Organismos Multilaterais e da nova divisão internacional do trabalho ${ }^{13}$, alcança a segunda década do século XXI, assumindo uma feição autoritária e ainda mais excludente, no que se refere à participação da ampla maioria da sociedade civil nos processos decisórios, para a definição das políticas econômicas e sociais. De acordo com Dardot e Laval,

O neoliberalismo só se sustenta e se reforça porque governa mediante a crise. Com efeito, desde os anos 1970, o neoliberalismo se nutre das crises econômicas e sociais que gera. Sua resposta é invariável: em vez de questionar a lógica que as provocou, é preciso levar ainda mais longe essa mesma lógica e procurar reforçá-la indefinidamente. Se a austeridade gera déficit orçamentário, é preciso acrescentar uma dose suplementar. Se a concorrência destrói o tecido industrial ou desertifica regiões, é preciso aguçá-la ainda mais entre as empresas, entre os territórios, entre as cidades. Se os serviços públicos já não cumprem sua missão, é preciso esvaziar esta última de qualquer conteúdo e privar os serviços dos meios que precisam. Se a diminuição de impostos para os ricos ou empresas não dão os resultados esperados, é preciso aprofundar ainda mais nisto, etc. (DARDOT e LAVAL, 2019, p.2).

Na periferia do sistema mundial do capitalismo, os países, de modo geral, sem perspectivas de sustentabilidade econômica e ambiental, em meio a um processo continuado e acelerado de erosão dos princípios básicos da democracia burguesa, enfrentam crises cíclicas, cada vez mais profundas, nas economias nacionais. Esse contexto criou as condições ideológicas favoráveis para a ascensão de grupos organizados em movimentos, associações e partidos de extrema-direita, que passaram a cooptar lideranças e amplos setores das classes populares, para a

${ }^{13}$ Como o Relatório da OIT indica, "espera-se que o crescimento da produtividade entre 2019 e 2021 alcance o seu pico mais elevado desde 2010, superando a média histórica de 2,1\% para o período de 1992-2018". A OIT refere-se à média mundial, visto que em muitos países — incluindo os EUA - o aumento da produtividade tem se mantido estagnado: ou seja, é o crescimento da produtividade em países como a China que puxa para cima a média global. Porém, os benefícios do aumento da produtividade não são satisfatoriamente distribuídos entre os trabalhadores, em termos de aumento salarial proporcional às suas contribuições. Os benefícios sobem diretamente para os donos do capital, o que aumenta a concentração de riqueza. $O$ trabalho está produzindo um excedente maciço, que poderia muito bem ser usado para melhorar o bem-estar geral da humanidade. Em vez disso, vai parar nos bolsos dos capitalistas. (Prashad, Vijay. Sobre iPhone11, tecnologia e "fim do trabalho", 2019). 
construção de regimes autoritários e ultraconservadores, com a promessa de transformação da sociedade, a partir da dimensão política e cultural concebida à luz de valores e referências do pensamento medieval. Exemplos desses regimes podem ser tomados das experiências recentes de eleição de Donald Trump nos Estados Unidos e de Jair Messias Bolsonaro no Brasil.

Além disso, os episódios recentes de intensos conflitos sociais que têm atingido a Venezuela, Equador, Bolívia, Chile e Colômbia, parecem indicar que a interferência dos Estados Unidos e do Brasil, em maior grau no caso do governo americano, e em menor escala, porém de modo efetivo, do governo brasileiro, se materializa por meio de ações políticas ilegítimas, de caráter intervencionista, ao desprezarem os princípios de soberania e autodeterminação dos povos, princípios historicamente construídos no âmbito das relações diplomáticas entre países democráticos. Por essa via, os Estados Unidos e o Brasil, de modo explícito, têm financiado grupos de oposição organizados para desestabilizarem os governantes, no caso da Venezuela e da Bolívia, com o objetivo de realizar o desmonte desses Estados, como também das proteções constitucionais aos recursos naturais de elevado valor de mercado, como o petróleo, gás natural, nióbio, lítio, etc.

\section{O desenvolvimento humano a partir da concepção do trabalho necessário à satisfação das necessidades humanas qualitativas}

A perspectiva de superação do trabalho alienado, aquele que se realiza no âmbito do modo de produção capitalista, seja sob a forma de trabalho manual ou trabalho intelectual, tendo como resultado a produção de objetos materiais ou de ideias, concepções, teorias e projetos, somente poderá ser vislumbrada se se conceber esse processo, como parte da totalidade do amplo e radical movimento de transformação da sociedade, e do modo como se organizam os homens e mulheres nos espaços de socialização de atividades práticas e teóricas, que visam a satisfazer suas necessidades qualitativas ou de ordem social e espiritual.

Marx, ao tratar das necessidades humanas, mesmo sem tê-las definido nos seus escritos, critica o conceito de necessidade da economia política clássica, concebida como categoria econômica, por compreender que a necessidade econômica constitui uma expressão da alienação (capitalista) das necessidades, numa sociedade na qual a finalidade da produção é a valorização do capital, em que 
o sistema de necessidades está baseado na divisão do trabalho e a necessidade somente aparece no mercado, sob a forma de demanda efetiva.

Heller, em sua obra Teoria das necessidades em Marx (1978, 1a ed; 1986, $2^{\text {a }}$ ed.), reconhece que o conceito de necessidades necessárias nos Grundrisse corresponde às necessidades naturais, enquanto no $O$ Capital fica destacada a diferença: as necessidades necessárias são aquelas surgidas historicamente e não dirigidas à mera sobrevivência. Marx considera na Miséria da Filosofia que existe uma contradição, ou seja, as necessidades necessárias dos trabalhadores não podem ser satisfeitas, porque não estão cobertas pela sua demanda efetiva, uma vez que prevalece como força predominante o capital, que induz a produção de necessidades a serem satisfeitas pela produção de produtos destinados ao consumo da própria burguesia.

Em Marx, as necessidades necessárias se distinguem, do ponto de vista empírico e filosófico. As necessidades necessárias são aquelas sempre crescentes, geradas mediante a produção material. Portanto, na sociedade dos produtores associados, que seria aquela sociedade que poderia suceder à capitalista, elas dizem respeito ao reino da necessidade, incluindo as necessidades de consumo e de produção, do ponto de vista material em correspondência à força e ao tempo de trabalho. Em confronto com essas, apresentam-se as necessidades espirituais e morais que não podem ser adquiridas com dinheiro e se relacionam à coletividade. Essas são reconhecidas como as necessidades livres características do reino da liberdade, no qual a necessidade, como categoria de valor referenciada na riqueza, é entendida em relação ao desenvolvimento dos indivíduos em sentido amplo, para além da concepção da economia política clássica, que reduz a riqueza à dimensão material.

Fundamentado na perspectiva histórico-dialética, Marx destaca o fato de que o capitalismo produz necessidades múltiplas e ricas, enquanto provoca o empobrecimento dos homens e converte o trabalhador em um ser isento de necessidades, dada a sua incapacidade de consumo no mercado capitalista. Assim, aparece o tema das necessidades radicais que constitui o motivo principal da obra de Marx. O homem rico em necessidades é um conceito filosófico e a essência humana, ainda que se materialize empiricamente, constitui uma categoria de valor. A alienação produzida no grau máximo deve produzir a necessidade de superá-la; a necessidade 
da riqueza é a realização da "essência" da espécie, que se pode conceber como a omnilateralidade.

No capitalismo, o homem fica reduzido a uma equivalência com aquilo que possui e suas qualidades e forças são derivadas de suas posses. A individualidade do ser se subsume na relação entre sua posse e a satisfação de suas carências. Ao contrário, na sociedade futura, conforme o gênero para si, a essência da espécie não poderá alienar-se do homem e, por conseguinte, não poderá ser reduzida a uma forma quantitativa. As necessidades e as capacidades humanas seriam de natureza qualitativa, e o qualitativo somente poderá ser trocado com o qualitativo, tal como observa Marx nos Manuscritos Filosóficos.

Entretanto, como ainda se reproduz o capitalismo, apenas vislumbrando--se a ideia de uma sociedade futura, seria necessário desdobrar as necessidades sociais para dar-Ihes concretude no plano empírico e no plano filosófico. Assim, Marx, No terceiro livro de O Capital, coloca a sociedade capitalista contraposta à sociedade dos produtores associados, o que quer dizer que as necessidades sociais constituem uma categoria de valor positivo, porque é a necessidade do modo de vida coletiva, do comunismo, em que os homens e mulheres vivem a sua sociabilidade de forma integral.

Os limites dentro dos quais a necessidade de mercadoria se apresenta no mercado - a demanda - se distingue quantitativamente da verdadeira necessidade social, variando muito, naturalmente, segundo as diversas mercadorias. A "necessidade social" referida à demanda é, portanto, mera aparência que não expressa as necessidades sociais reais da classe operária, inclusive as transforma no seu contrário. Então, para Marx, as necessidades sociais reais correspondem ao conteúdo empírico e sociológico das necessidades necessárias. Isto quer dizer a média das necessidades individuais desenvolvidas historicamente, transmitidas nos usos e dotadas de componentes morais.

Nos Manuscritos econômicos-filosóficos, Marx identifica que as necessidades sociais representam as necessidades autênticas totalmente conscientes, enquanto as "sociais", que emergem no mercado, assinalam as possibilidades de satisfação das primeiras em uma determinada sociedade. As "necessidades sociais", que podem ser adquiridas mediante o valor de troca, são irrelevantes do ponto de vista das outras necessidades. Para Marx, essas constituíam a forma mais característica do fenômeno 
da alienação. Outras "necessidades sociais" correspondem à satisfação social e, às vezes comunitárias, das necessidades. Esta é uma interpretação não econômica que serve para expressar o fato de que os homens possuem necessidades não somente produzidas socialmente, mas também necessidades unicamente suscetíveis de satisfação mediante a criação de alternativas coletivas, como as organizações e instituições sociais. Como exemplo, tem-se a saúde e a educação pública, necessidade cultural e necessidade comunitária, que somente podem ser satisfeitas na vida comunitária. Embora a categoria não seja por si só econômica, pode-se destacar um aspecto econômico apontado por Marx na Crítica ao Programa de Gotha, no qual afirma que deve ser descontado um percentual da renda integral do trabalho, para se destinar à satisfação coletiva das necessidades. Em relação às necessidades sociais puramente materiais, Marx atribui um caráter de relativa estabilidade quantitativa - sua quantidade só deveria aumentar paralelamente ao crescimento da população.

Marx especula que essas necessidades seriam conscientes e pessoais e sua satisfação será tão importante que limitará outras necessidades humanas. Quando cessa o domínio das coisas sobre o homem, quando as relações inter-humanas não aparecem mais como relações entre coisas, então prevalecem as necessidades subordinadas ao desenvolvimento dos indivíduos, para a auto- realização da personalidade, tornando-se predominantes as dimensões qualitativas, que se expressam de modo variado sob atividades sociais e culturais.

Uma das estruturas interdependentes essenciais do capitalismo como "formação" é a estrutura das necessidades. Para poder funcionar na forma característica da época de Marx, para poder subsistir como "formação social", o capitalismo no interior de sua estrutura de necessidades, inclui algumas de impossível satisfação em seu seio. Com o reconhecimento das necessidades radicais, insuperáveis no capitalismo, como elementos constitutivos do movimento de superação por meio da revolução total, Marx reafirma o processo histórico como a única possibilidade real de transformação engendrada pela luta de classes, indicando que o antagonismo entre o proletariado e a burguesia é uma luta de classe contra classe, luta que poderá levar a uma revolução total, pela qual poderiam ser superadas as antinomias entre opostos. 
Somente a luta do sujeito coletivo é capaz de realizar a nova sociedade; sua revolução radical e total. Por sua vez, o dever coletivo se realiza necessariamente, posto que o próprio "corpo social" capitalista gera as necessidades radicais e seus portadores. Na sociedade dos "produtores associados" preconizada por Marx, as antinomias citadas deixam de existir e a via para superá-las é a revolução total. Quando cessa a oposição entre sujeito e objeto, a riqueza do gênero e a do indivíduo "coincidem", como afirma Marx nos Manuscritos econômicos-filosóficos de 1844.

O reino da produção (o intercâmbio orgânico da sociedade com a natureza) continua sendo o reino da necessidade. Porém, a necessidade fica subordinada à liberdade. Liberdade, necessidade, teleologia e riqueza social do futuro não têm o mesmo conteúdo produzido na sociedade capitalista. A sociedade futura, em cada um dos seus aspectos estruturais, é radicalmente distinta da capitalista, e por isso tão somente pode realizar-se através de uma revolução total. Apesar disso, o desenvolvimento capitalista das forças produtivas é o que gera a possibilidade desta revolução social total.

Nesse sentido, Marx afirma que uma revolução social total pressupõe e ao mesmo tempo implica a superação da relação estrutural entre teoria e práxis desenvolvida no capitalismo, e também a superação da estrutura burguesa das necessidades em seu conjunto. Para alcançar seus objetivos, a revolução política é necessária, todavia não está em condição de realizar esta estrutura radicalmente nova. Para satisfazer as necessidades radicais, é necessário transcender a sociedade capitalista em toda sua estrutura, incluída a própria estrutura das necessidades.

A classe trabalhadora só pode libertar-se a si mesma se libertar a toda a humanidade, realizando a liquidação positiva da propriedade privada e a superação da alienação. Portanto, a possibilidade de se expandir o desenvolvimento da espécie humana, em contraposição à sua subordinação ao capital, requer que sejam constituídas, ainda no âmbito do capitalismo, novas formas de trabalho, produção, circulação de bens materiais e imateriais.

Nesse sentido, do esforço realizado pelas lutas anticapitalistas, têm se produzido experiências no "mundo do trabalho associado" e gerado "embriões de educação para além do capital”, como nos apresenta Novaes, et al. (2018), ao publicar juntamente com Silva, Alaniz, Rodrigues, Pires, Santos e Faria o resultado de suas 
pesquisas. ${ }^{14}$ Explicitando sua aproximação à concepção de Mészáros, Novaes reitera a reflexão seminal do pensador húngaro, ao afirmar que:

a transição socialista se dá no âmbito da proposta que formula de uma mudança global que tem por objetivo a transcendência do 'sociometabolismo do capital'. Sua teoria segue em busca das exigências qualitativamente mais elevadas da nova forma histórica, o socialismo pós-capital (e não pós-capitalista), onde o ser humano possa desenvolver sua 'rica individualidade'. (NOVAES, 2018, p. 29).

A compreensão da transformação radical do modo de produção capitalista pressupõe a luta no âmbito da economia, da política, da cultura e da educação, de forma sistemática, programática e simultânea, considerando que se faz necessário realizar o combate em todas as dimensões, conjugando os movimentos de destruição das forças submissas ao capitalismo e de construção da alternativa socialista. Segundo Mészáros,

Aqueles que pensam que a alternativa hegemônica socialista é "irreal" - e, sem qualquer interesse disfarçado, defenderam a todo custo a ordem estabelecida - deveriam se perguntar: é realmente possível e logicamente sustentável projetar a permanência de um sistema sociometabólico de reprodução baseado nos imperativos materiais fetichistas da lógica destrutiva do capital? Os resignados a suportar a inércia do "realismo" do capital que se autoperpetua podem seriamente continuar defendendo que a incontrolabilidade destrutiva do capital não está lançando perspectivas cada vez mais sombrias no horizonte da sobrevivência humana? Agora, até mesmo os defensores mais acríticos da ordem vigente são obrigados a reconhecer que os problemas mais sérios ainda estão diante de nós. A "única" diferença é que, confundindo desejo com realidade eles esperam do poder repressivo do capital a solução definitiva para todos esses problemas. $\mathrm{Na}$ verdade, porém, mais irreal não é a alternativa hegemônica socialista ao domínio do capital em todas as suas formas historicamente conhecidas e ainda possíveis, mas a projeção gratuita de que a humanidade pode sobreviver por muito mais tempo ainda dentro dos limites estruturais necessariamente destrutivos do modo estabelecido de reprodução sociometabólica. (MÉSZÁROS, 2011, p.921).

\section{Algumas considerações para reflexão continuada}

Ao se apresentar no presente texto um breve resgate da história recente das relações entre capital, trabalho e desenvolvimento humano, o que se pretendeu foi contribuir para agudizar a perspectiva crítica da historiografia da educação, dada a

\footnotetext{
${ }^{14}$ NOVAES, Henrique Tohan et al. Mundo do trabalho e embriões de educação para além do capital. Marília, Lutas anticapital, 2018.
} 
necessidade histórica de se realizar o enfrentamento das investidas do capital, na atualidade, sobre o pensamento crítico, utilizando-se de formas arcaicas e sórdidas de desqualificação da ciência, da educação e da cultura, prenhes de potência emancipatória, quando não transformadas em mercadoria.

Na realidade, desdobra-se sob nossos olhos estupefatos uma situação histórica que ameaça o futuro das crianças, dos adolescentes e jovens, cidadãos em formação para o exercício de sua cidadania no século XXI, em que se sucedem "décadas perdidas" em consequência das imposições do capitalismo no seu sistema de reprodução mundial, entre as quais aquelas condicionalidades determinantes de um quadro de perdas irreparáveis, na condição de existência física e psíquica dos trabalhadores e trabalhadoras em diferentes setores de produção e de serviços.

Embora possa parecer impossível uma regressão histórica a períodos do passado remoto, as manifestações e ações dirigidas contra a produção teórico-científica derivadas do período iluminista, evidenciam o retrocesso que remonta ao obscurantismo da Idade Média, rearticulando em novas bases materiais a ideologia e os valores da Idade das Trevas, sob a tutela dos Estados Ditatoriais e das Igrejas Ultraconservadoras, que adotam concepções análogas ao período em que vigorou a "santa inquisição".

Esta fase pode ser caracterizada não apenas como mais uma etapa do desenvolvimento capitalista, mas, sim, como um regime instaurado a exemplo do que pretenderam o fascismo e o nazismo sintetizados na expressão de Thatcher, quando afirmou: "there is no alternative". Isto significa a expressão acabada do pensamento único com a interdição do dissenso e a desqualificação de qualquer interlocutor que se coloque em rota de colisão com o pensamento hegemonicamente imposto.

Entretanto, apesar da magnitude do ataque às forças progressistas, a história não tem fim e a contradição a impulsiona em direção a processos não definidos previamente, ou seja, o imponderável tem forte influência sobre a história da humanidade. Ainda assim, o que se coloca efetivamente como desafio para as gerações atuais de educadores é, em última instância, lutar pela emancipação humana, por meio do trabalho pedagógico e político cotidiano, realizando a práxis revolucionária desde o nível micro de atuação na transformação da sociedade.

Vislumbrando essa possibilidade histórica da luta pela emancipação humana, finaliza-se esta reflexão, levantando-se novas questões fundamentais para a 
continuidade do esforço teórico-prático dos coletivos de militantes. Pois, sem este tudo poderá permanecer como está, ou pode inclusive alcançar níveis ainda mais agudos de desconstrução das sociedades, comprometendo a própria existência da humanidade na sua forma de manifestação mais avançada, que alcançamos até o presente, após muitos séculos de evolução humana de caráter físico e psíquico permeado por diferenças e contradições.

Dadas essas circunstâncias históricas, que enlaçam elementos de um passado remoto e de um presente recente, em que se torna visível a linha de continuidade da história da exploração dos seres humanos, sob as formas mais violentas e, também, sob formas as mais edulcoradas que já se pôde ver, apresentam-se algumas questões fundamentais: De que modo poder-se-á garantir às futuras gerações as possiblidades de superação desse processo contínuo e efetivo de encolhimento da condição humana? Quais as possibilidades de se resistir ao processo de reducionismo da perspectiva de desenvolvimento humano como efeito da liquefação das necessidades humanas no mercado capitalista?

\section{Referências}

ANTUNES, Ricardo; BRAGA, Ruy (orgs). Infoproletários : degradação real do trabalho virtual. São Paulo:Boitempo, 2009.

DARDOT, Pierre; LAVAL, Christian. A nova razão do mundo: ensaio sobre a sociedade neoliberal. São Paulo: Boitempo, 2016. A nova fase do neoliberalismo. Viento Sur, Boletim Outras

Mídias, 27/09/2019,.

HELLER, Agnes. Teoria das necessidades em Marx. Barcelona: Ediciones Peninsula, 1986.

JUNIOR, Valdinei Santos de Aguiar; VASCONCELLOS, Luiz Carlos Fadel de. A importância histórica e social da infância para a construção do direito à saúde no trabalho. Saúde Soc.São Paulo, v.26, n.1, p.271-285,2017.

LINHART, Danièle. A desmedida do capital. São Paulo:Boitempo, 2007, p.117.

MAGNO, Attila; BARBOSA, Silva. O empreendedor de si mesmo e a flexibilização no mundo do trabalho. Rev. Sociol. Política, Curitiba, v. 19, n. 38, p. 121-140, fev. 2011.

MÉSZÁROS, István. Para além do capital: rumo a uma teoria da transição. São Paulo, Boitempo, 2011. 
NOVAES, Henrique Tohan et al. Mundo do trabalho e embriões de educação para além do capital. Marília, Lutas anticapital, 2018.

PRASHAD, Vijay. Sobre iPhone11, tecnologia e "fim do trabalho", Boletim Outras Palavras, 26/09/ 2019.

RÁDIO Pião Informativo Operário - Ano XV, ㄲ76, março/abril, 2019, p.2.

ROSAR, Orlando Oscar. Política econômica ortodoxa, reprimarização da pauta de exportações e expansão do agronegócio no Brasil. Trabalho apresentado no IX Congresso da APDEA (Associação Portuguesa de Economia Agrária), Lisboa/Oeiras, 14 a 18 de outubro de 2019.

VENCO, Selma. Centrais de teleatividades: o surgimento dos colarinhos furta-cores? IN: ANTUNES, Ricardo; BRAGA, Ruy (orgs). Infoproletários : degradação real do trabalho virtual. São Paulo:Boitempo, 2009, p.159. 